\title{
Studi Tinjauan Pustaka: Risiko Kejadian Kanker Paru pada Penderita Tuberkulosis Paru.
}

\section{Literature Review Study: Risk of Lung Cancer Occurrence in Patients with Lung Tuberculosis.}

\author{
Fariha Ramadhaniah ${ }^{\mathrm{a}^{*}}$, Syahrizal Syarif ${ }^{\mathrm{b}}$ \\ a* Program Studi Magister Epidemiologi, Fakultas Kesehatan Masyarakat Universitas Indonesia, Depok 16424, Indonesia \\ ${ }^{\mathrm{b}}$ Departemen Epidemiologi, Fakultas Kesehatan Masyarakat Universitas Indonesia, Lantai 1 Gedung A, Kampus UI Depok, Indonesia
}

\section{A B S T RA K}

Indonesia merupakan satu dari lima negara di dunia dengan insiden kasus TB yang tinggi, sementara itu kanker paru di Indonesia merupakan kasus keganasan utama yang paling sering terjadi. Untuk melihat gambaran risiko kejadian kanker paru diantara penderita TB paru, dilakukan studi tinjauan pustaka pada sepuluh jurnal yang dipublikasikan melalui Pubmed pada tahun 2009-2019. Kriteria inklusi dalam pemilihan jurnal yaitu TB paru sebagai faktor risiko dan kanker paru primer sebagai outcome, sedangkan kriteria ekslusi adalah jurnal yang merupakan tinjauan pustaka sistematis, skrining, diagnosis, dan evaluasi hasil pengobatan yang berkaitan dengan infeksi TB dan kanker paru. Analisis deskriptif menunjukan subjek sebagian besar merupakan laki-laki dan berusia antara 40-60 tahun. Pada kelompok TB paru didominasi perokok, peminum alkohol, memiliki penyakit paru lainnya dan komorbiditas. Penderita TB paru secara konsisten mempunyai risiko yang lebih besar untuk terjadinya kanker paru dibandingkan penderita non TB paru. Dari delapan penelitian kohor, menunjukkan hubungan secara statistik bermakna dengan nilai RR 1,37-6,1. Dari dua penelitian kasus kontrol, hanya satu yang menunjukkan hubungan secara statitstik bermakna dengan kisaran nilai OR 1,52 - 3,21 spesifik pada jenis kanker paru tertentu. Terdapat tiga studi menampilkan resiko yang lebih besar pada interval lima tahun pertama sejak terdiagnosanya TB paru hingga berkembang menjadi kanker paru. Studi tinjauan pustaka ini menyimpulkan bahwa penyakit infeksi TB paru berpotensi untuk dapat menimbulkan kanker paru, hal ini dapat menjadi bahan pertimbangan dalam upaya intervensi preventif kanker paru.

Kata kunci: kanker paru, tuberkulosis, faktor risiko

\section{Pendahuluan}

Beban penyakit menular dan tidak menular di Indonesia semakin meningkat mengharuskan Indonesia harus memiliki startegi dalam penentuan prioritas penyelesaian masalah kesehatan. Kondisi ini disebut sebagai beban ganda kesehatan. Jumlah kasus baru TB di Indonesia sebanyak 420.994 kasus pada tahun 2017. Jumlah ini membuat Indonesia menjadi satu dari lima negara di dunia dengan insiden kasus tertinggi yaitu India, Indonesia, China, Philipina, dan Pakistan. Berdasarkan jenis kelamin, jumlah kasus baru TBC tahun 2017 pada laki-laki 1,4 kali lebih besar dibandingkan pada perempuan. TB merupakan satu

\section{A B S T R A C T}

Indonesia is one of the five countries in the world with a high TB incidence, while lung cancer in Indonesia is the most common malignancy. Describing risk of lung cancer occurrence in patients with lung tuberculosis (TB), a literature review was conducted in journals published in 2009-2019. Inclusion criterias in selecting journal were pulmonary TB as risk factors and primary lung cancer as outcome, while exclusion criteria in selecting journals which systematic review, screening, diagnosis, and evaluation of treatment related to TB infections and lung cancer. Descriptive analysis showed that the subjects were mostly male with age group between 40-60 years old. Majority in the pulmonary TB group were smokers, alcohol drinker, having others lung disease and comorbidities. Patients with pulmonary TB consistently have a greater risk for the occurrence of lung cancer than patients with non-pulmonary TB. From the cohort's research, they showed a statistical relationship with RR 1.37 - 6.1. Two case-control studies, only one showed an association with statistical contributions in OR range of 1.52 - 3.31 specific to certain histology of lung cancer. There are three studies that demonstrate greater risk in the first five-year interval from the diagnosis of pulmonary TB to develop lung cancer. This literature review study concludes that pulmonary TB infection has the potential to cause lung cancer, as a consideration in efforts interventions to prevent lung cancer.

Key words: lung cancer, tuberculosis, risk factors

dari 10 penyebab kematian dengan penyebab utama agen infeksius di Indonesia. ${ }^{1}$ Sementara itu kejadian kanker paru di Indonesia berdasarkan Globocan 2018, merupakan kasus keganasan utama yang paling sering terjadi dimana pada laki-laki, kanker paru menempati urutan pertama dari seluruh keganasan sebesar 19,4 kasus per 100.000 penduduk. Sementara pada perempuan, kanker paru menempati urutan keempat dari seluruh keganasan sebesar 6,0 kasus per 100.000 penduduk. $^{2}$

*Korespondensi: Fariha Ramadhaniah, Program Magister Epidemiologi, Fakultas Kesehatan Masyarakat Universitas Indonesia, Gedung A, Lantai 1 Kampus UI Depok, Indonesia. Email: fariha2105@gmail.com HP. $+628569908380$ 
Beban penyakit menular dan tidak menular di Indonesia kian menjadi perhatian karena kejadian suatu penyakit dapat menjadi faktor risiko terhadap peningkatan kejadian penyakit lainnya. Dalam hal ini, suatu studi kohort telah membuktikan bahwa insiden kanker paru sebesar 11 kali lipat lebih tinggi pada kelompok pasien dengan TB daripada bukan TB $(26,3$ berbanding 2,41 per 10.000 orang-tahun). ${ }^{3}$ Studi kohort lainnya menggambarkan insiden rasio yang telah distandarisasi memprediksi risiko terjadinya kanker paru pada pasien TB dibandingkan populasi umum adalah 3,40 lebih tinggi. ${ }^{4}$

Kanker paru primer adalah keganasan yang terjadi di organ paru bukan merupakan anak sebar dari kanker pada organ lain, merupakan kanker yang paling sering didiagnosis $(11,6 \%$ dari keseluruhan kasus kanker) dan penyebab utama kematian akibat kanker di dunia $(18,4 \%$ dari keseluruhan kematian akibat kanker) berdasarkan Globocan 2018. ${ }^{5}$ Proses peradangan telah lama dikaitkan dengan perkembangan kanker. TB dengan lebih dari $80 \%$ kasus terutama menyerang paru mengakibatkan proses peradangan kronis. ${ }^{6}$

Tujuan dari studi tinjauan pustaka ini adalah untuk memberikan gambaran mengenai risiko kejadian kanker paru diantara penderita TB paru. Hasil dari studi ini diharapkan dapat digunakan sebagai informasi yang dapat dipakai sebagai langkah awal membawa kepada suatu tinjauan kepustakaan sistematis dan meta-analisis lebih lanjut.

\section{Metode}

Penelitian ini adalah suatu studi tinjauan pustaka dengan tahapan meringkas, membandingkan, menganalisis dan mensintesis beberapa penelitian mengenai risiko kejadian kanker paru diantara penderita TB paru. Artikel terpilih yang memenuhi syarat adalah jurnal yang dipublikasikan melalui Pubmed, jurnal ilmiah internasional berbahasa Inggris, diterbitkan tahun 2009-2019 (tanggal terbit 2009/01/ 01" sampai 2019/11/01 terbit), kata kunci yang dipakai untuk mencari dan menyeleksi jurnal adalah: "Tuberculosis or Mycobacterium tuberculosis", "lung cancer", "risk factor".

Subjek dalam studi tinjauan pustaka ini adalah tuberkulosis paru sebagai paparan dan kanker paru sebagai penyakit. Artikel yang dipilih berdasarkan kriteria inklusi yaitu jurnal yang dalam penelitiannya meneliti hubungan antara infeksi TB paru dengan kejadian kanker paru primer, baik menggunakan desain studi kohort (retrospektif ataupun prospektif), yang dapat memperlihatkan perjalanan penyakit, etiologi, dan kecepatan dari paparan hingga menjadi penyakit, ataupun yang menggunakan desain studi kasus kontrol. Kriteria eksklusi adalah jurnal yang merupakan tinjauan pustaka sistematis, skrining, diagnosis, dan evaluasi hasil pengobatan yang berkaitan dengan infeksi tuberkulosis, dan kanker paru.

Ditemukan sepuluh artikel yang memenuhi persyaratan, dan selanjutnya terhadap artikel-artikel tersebut dilakukan tahapan meringkas, membandingkan, menganalisis dan mensintesis. Dalam tahapan meringkas, dilakukan dengan membuat ringkasan secara sistematis yang disajikan dalam tabel mengenai identitas peneliti, lokasi penelitian, nama jurnal, tujuan, desain, variabel kovariat, sumber data, jumlah sampel, gambaran demografi dan hasil penelitian. Hasil dari tahap ini dapat dilihat pada tabel 1.

Pada tahap membandingkan, dari tabel hasil ringkasan dilakukan perbandingan dari tujuan, metode, hasil dan simpulan dari penelitian pada artikel-artikel yang ditinjau. Hal ini diuraikan secara singkat pada bagian hasil. Tahapan menganalisis, dilakukan terhadap setiap artikel untuk memastikan TB paru sebagai faktor risiko dan kanker paru sebagai penyakit (outcome), memenuhi kriteria inklusi dan eksklusi artikel yang dipilih, dan secara kualitatif memutuskan apakah artikel yang dimaksud layak untuk masuk kedalam tinjauan pustaka atau tidak. Pada tahap mensintesis, menarik benang merah atau kesimpulan secara garis besar dari artikel yang ditinjau sehingga dapat menilai apakah risiko kejadian kanker paru pada penderita tuberkulosis paru menghasilkan hubungan yang konsisten diantara kesepuluh artikel.

\section{Hasil}

Dalam studi tinjauan pustaka ini dipilih sepuluh artikel yang berasal dari beberapa negara dengan subjek yang berasal dari fasilitas kesehatan maupun populasi dengan rentang waktu studi yang bervariasi. Ringkasan dari sepuluh jurnal terdapat pada tabel 1. Sebagian besar subjek dari penelitian adalah laki-laki dengan rentang usia pada kelompok umur 40-60 tahun. Pada subjek dengan TB didominasi karakteristik dengan proporsi yang lebih besar pada perokok, peminum alkohol, mengidap penyakit paru lainnya dan memiliki komorbiditas yang lebih banyak dibanding kelompok pembanding.

Artikel yang terdapat dalam studi tinjauan pustaka ini memiliki tujuan penelitian menilai risiko tuberkulosis paru terhadap terjadinya kanker paru secara spesifik, delapan ${ }^{3-4,7-12}$ dari sepuluh artikel dilakukan dengan desain penelitian kohort secara 
Ramadhaniah \& Syarif, Studi Tinjauan Pustaka: Risiko Kejadian Kanker Paru pada Penderita Tuberkulosis Paru.

Tabel Ringkasan Jurnal Ilmiah yang Ditelaah

\begin{tabular}{|c|c|c|c|c|}
\hline No & $\begin{array}{l}\text { Penulis, Lokasi } \\
\text { Penelitian, Jurnal }\end{array}$ & $\begin{array}{c}\text { Tujuan, Desain Penelitian, dan } \\
\text { Variabel Kovariat }\end{array}$ & $\begin{array}{c}\text { Sumber Data dan Jumlah } \\
\text { Sampel }\end{array}$ & Hasil \\
\hline 1. & $\begin{array}{l}\text { Yang-Hao } \mathrm{Yu}^{3} \\
\text { (Taiwan) } \\
\text { Journal of Thoracic } \\
\text { Oncology. 2011: 6: } \\
\text { 32-37 }\end{array}$ & $\begin{array}{l}\text { Mengeksplorasi pengidap TB paru } \\
\text { dikaitkan dengan peningkatan } \\
\text { risiko kanker paru. } \\
\text { Kohort prospektif. } \\
\text { Kovariat: jenis kelamin, umur, } \\
\text { pekerjaan, komorbiditas: } \\
\text { hipertensi, hiperlipidemia, diabetes, } \\
\text { penyakit paru obstruktif kronik, } \\
\text { status merokok. }\end{array}$ & $\begin{array}{l}\text { Sumber data berasal dari } \\
\text { program The Universal } \\
\text { National Health Insurance } \\
\text { (NHI) Taiwan. } \\
\text { Subjek studi yang memenuhi } \\
\text { syarat 4.480 subjek dengan } \\
\text { TB dan 712,392 subjek tidak } \\
\text { TB. } \\
\text { Random sampling. } \\
\text { Follow up } 2001-2007 .\end{array}$ & $\begin{array}{l}\text { HR 4,37 (95\% [CI]: 3,56-5,36) untuk } \\
\text { kohort TB setelah penyesuaian variabel } \\
\text { sosiodemografi atau 3,32 (95\% CI: 2,70- } \\
\text { 4,09) setelah penyesuaian untuk } \\
\text { penyakit paru obstruktif kronik (PPOK), } \\
\text { kanker terkait dengan merokok (selain } \\
\text { kanker paru). } \\
\text { Insiden kanker paru adalah sekitar } 11 \\
\text { kali lipat lebih tinggi pada kohort pasien } \\
\text { dengan tuberkulosis daripada subyek } \\
\text { bukan tuberkulosis (26,3 berbanding } \\
\text { 2,41 per } 10.000 \text { orang-tahun). }\end{array}$ \\
\hline 2. & $\begin{array}{l}\text { D. F. Simonsen } \\
\text { (Denmark) } \\
\text { The International } \\
\text { Journal of } \\
\text { Tuberculosis and } \\
\text { Lung Disease } \\
\text { 2014;18(10):1211- } \\
\text { 9. }\end{array}$ & $\begin{array}{l}\text { Menginvestigasi jangka pendek dan } \\
\text { jangka panjang risiko kanker pada } \\
\text { pasien TB aktif. } \\
\text { Kohort. } \\
\text { Kovariat: jenis kelamin, umur, } \\
\text { negara asal, skala komorbiditas, } \\
\text { status COPD, peminum alkohol, } \\
\text { status HIV, }\end{array}$ & $\begin{array}{l}\text { Sumber data Danish National } \\
\text { Registry of Patients (DNRP) } \\
\text { Studi kohort melibatkan } \\
\text { 15.024 pasien TB } \\
\text { Follow-up: median 8,5 tahun } \\
\text { (rentang antar kuartil 3.1- } \\
\text { 14.9) }\end{array}$ & $\begin{array}{l}\text { SIR kanker paru 3.40 (95\%CI 3.09- } \\
\text { 3.74). } \\
\text { Risiko absolut terjadinya kanker tiga } \\
\text { bulan setelah TB 1.83\% (SIR 11.09, } \\
\text { 95\%CI 9.82-12.48), dengan } \\
\text { peningkatan yang sangat besar pada } \\
\text { kanker paru (SIR 40.9) } \\
\text { Antara masa follow-up } 3 \text { bulan dan } 5 \\
\text { tahun, SIR untuk semua kanker adalah } \\
\text { 1,59 (95\% CI 1,46-1,72), peningkatan } \\
19 \text { dan } 3 \text { kali lipat untuk mesothelioma } \\
\text { dan kanker paru. } \\
\text { IR = 11.628,06 per } 100.000 \text { orang } \\
\text { tahun. }\end{array}$ \\
\hline 3. & $\begin{array}{l}\text { Eric A. Engels } \\
\text { (China) } \\
\text { International Journal } \\
\text { of Cancer. 2009 } \\
\text { March 1: 124(5): } \\
\text { 1183-1187 }\end{array}$ & $\begin{array}{l}\text { Memeriksa secara rinci hubungan } \\
\text { antara TB dan risiko selanjutnya } \\
\text { terhadap kanker paru. } \\
\text { Kohort retrospektif. } \\
\text { Kovariat : jenis kelamin, umur, } \\
\text { tingkat pendidikan, pemakaian batu } \\
\text { bara dalam memasak, status } \\
\text { merokok, jumlah rokok per hari, } \\
\text { status penyakit paru; asma, } \\
\text { bronchitis kronik, empisema, } \\
\text { riwayat keluarga dengan TB, } \\
\text { aktivitas berjalan per hari, rata-rata } \\
\text { jumlah ruangan di rumah. }\end{array}$ & $\begin{array}{l}\text { Subjek penelitian sebanyak } \\
246 \text { dengan TB. Sample } \\
\text { merupakan petani yang } \\
\text { tinggal di wilayah tertentu } \\
\text { dengan memperhatikan } \\
\text { kriteria tempat tinggal dan } \\
\text { kelengkapan identitas. }\end{array}$ & $\begin{array}{l}\text { Mortalitas kanker paru secara } \\
\text { substansial lebih tinggi pada subyek } \\
\text { dengan tuberkulosis daripada yang } \\
\text { tidak ( } 25 \text { vs } 3.1 \text { per } 1000 \text { orang-tahun) } \\
\text { (HR 6.1, 95\% CI 4.3-8.7). } \\
\text { Hubungan terutama muncul dalam lima } \\
\text { tahun pertama (HR 6,7-13), tetap kuat } \\
\text { pada 5-9,9 tahun (HR 3.4, 95\% CI 1.3- } \\
\text { 9.1) dan lebih dari } 10 \text { tahun (HR 3.0, } \\
\text { 95\% CI 1.3-7.3) setelah diagnosis } \\
\text { tuberkulosis. } \\
\text { IR kanker paru dengan TB 0,2 per } 1000 \\
\text { orang-tahun. }\end{array}$ \\
\hline 4. & $\begin{array}{l}\text { Chen-Yi Wu, M } \\
\text { (Taiwan) } \\
\text { Cancer 2011: } \\
\text { 117:618-24 }\end{array}$ & $\begin{array}{l}\text { Menginvestigasi risiko kanker paru } \\
\text { setelah infeksi TB paru. } \\
\text { Kohort retrospektif. } \\
\text { Kovariat : jenis kelamin, umur, } \\
\text { komorbiditas yaitu diabetes } \\
\text { melitus, gagal ginjal kronis, } \\
\text { penyakit autoimun, penyakit paru } \\
\text { obstruksi kronik. }\end{array}$ & $\begin{array}{l}\text { Sumber data berasal dari The } \\
\text { National Health Insurance } \\
\text { Taiwan. } \\
\text { Sebanyak pasien TB } 5.657 . \\
\text { Follow-up: } 1 \text { s.d maksimal } 12 \\
\text { tahun. }\end{array}$ & $\begin{array}{l}\text { IRR: } 1.76 \text { CI } 1.33-2.32 \mathrm{p}<0.001 \\
\text { Rata-rata interval sejak TB ke diagnosa } \\
\text { kanker paru } 3.95 \text { tahun }(95 \% \text { CI, 3.31- } \\
\text { 4.59). } \\
\text { IR kanker paru dengan TB } 269 \text { per } \\
100.000 \text { vs } 153 \text { per } 100.000 \text { orang } \\
\text { tahun. }\end{array}$ \\
\hline 5. & $\begin{array}{l}\text { S-C Kuo }{ }^{9} \text { (Taiwan) } \\
\text { British Journal of } \\
\text { Cancer (2013) 109, } \\
\text { 229-234 }\end{array}$ & $\begin{array}{l}\text { Menilai secara sistematis risiko } \\
\text { bukan kanker paru setelah infeksi } \\
\text { TB. } \\
\text { Kohort. } \\
\text { Kovariat: jenis kelamin, umur, } \\
\text { kanker lainnya. }\end{array}$ & $\begin{array}{l}\text { Sampel diambil dari Taiwan } \\
\text { National Health Insurance } \\
\text { database } \\
\text { Total } 6.699 \text { pasien dengan } \\
\text { TB. } \\
\text { Median follow up } 3.8 \text { (1.3- } \\
\text { 6.9). }\end{array}$ & $\begin{array}{l}\text { Risiko keseluruhan kanker pada semua } \\
\text { pasien dengan TB yang baru didiagnosis } \\
\text { lebih tinggi daripada populasi umum } \\
\text { (SIR 2,07, } 95 \% \text { (CI), 1,90-2,26). } \\
\text { Pada semua pasien dengan TB yang } \\
\text { baru didiagnosis, SIR kanker meningkat } \\
\text { secara signifikan, kanker paru (SIR 4.09, } \\
95 \% \text { (CI), 3.48-4.78. } \\
\text { IR = 1.836,07 per } 100.000 \text { orang tahun. }\end{array}$ \\
\hline
\end{tabular}

* IRR: Insidens rate ratio, IR: Incidence Rates, SIR: standardized, incidence ratio, RR: relative risk, HR: hazard ratios, CI: confidence interval 


\begin{tabular}{|c|c|c|c|c|}
\hline No & $\begin{array}{l}\text { Penulis, Lokasi } \\
\text { Penelitian, Jurnal }\end{array}$ & $\begin{array}{c}\text { Tujuan, Desain Penelitian, dan } \\
\text { Variabel Kovariat }\end{array}$ & $\begin{array}{l}\text { Sumber Data dan Jumlah } \\
\text { Sampel }\end{array}$ & Hasil \\
\hline 6. & $\begin{array}{l}\text { Vincent Yi-Fong Su}{ }^{10} \\
\text { (Taiwan) } \\
\text { Medicine Journal. } \\
\text { Volume 95, Number } \\
\text { 4, January 2016 }\end{array}$ & $\begin{array}{l}\text { Menginvestigasi risiko kanker di } \\
\text { antara TB dengan atau tanpa aktivasi } \\
\text { TB berikutnya. } \\
\text { Kohort retrospektif. } \\
\text { Kovariat: jenis kelamin, umur, } \\
\text { komorbiditas; diabetes melitus, } \\
\text { penyakit jantung, gagal jantung, stroke, } \\
\text { hipertensi, lupus, rematik artitis, } \\
\text { penyakit ginjal kronis, sirosis hati, } \\
\text { asma, penyakit paru obstruksi kronik, } \\
\text { bukan TB mikrobakteri dan tingkat } \\
\text { penghasilan. }\end{array}$ & $\begin{array}{l}\text { Sumber data The National } \\
\text { Health Insurance Research } \\
\text { Database (NHIRD) sebagai } \\
\text { database program dari The } \\
\text { Taiwan National Health } \\
\text { Insurance (NHI). } \\
\text { Peneliti mengidentifikasi } \\
11.522 \text { orang yang telah } \\
\text { diklasifikasikan sebagai kontak } \\
\text { TB. } \\
\text { Kelompok pembanding } \\
\text { sebanyak } 46.088 \text { tanpa kontak } \\
\text { TB dipilih secara acak. } \\
\text { Periode dari } 1 \text { Januari } 1996 \text { - } \\
\text { 31 Desember 2012. }\end{array}$ & $\begin{array}{l}\text { Setelah dianalisis multivariat, HR untuk } \\
\text { kanker di antara pasien dengan TB laten } \\
(2,29 ; \mathrm{CI} 95 \%, 1,26-4,17 ; \mathrm{P}<0,001) \text {. } \\
\text { Ada peningkatan insiden kanker untuk } \\
\text { beberapa jenis kanker spesifik, termasuk } \\
\text { kanker paru (HR 2.69). } \\
\\
\text { Insiden dalam kelompok kontak TB dan } \\
\text { kelompok pembanding adalah } 55,27 \text { dan } \\
57,03 \text { orang per } 10.000 \text { orang-tahun, tidak } \\
\text { berbeda secara signifikan (uji log-rank, } \mathrm{P}= \\
0,714 \text { ). }\end{array}$ \\
\hline 7. & $\begin{array}{l}\text { Jong-Myon Bae }{ }^{11} \\
\text { (Korea Selatan) } \\
\\
\text { Journal of Korean } \\
\text { Medical Science } \\
\text { 2013: 28: 896-900 }\end{array}$ & $\begin{array}{l}\text { Mengevaluasi riwayat tuberkulosis } \\
\text { paru sebagai faktor risiko kanker paru } \\
\text { pada laki-laki perokok. } \\
\text { Kohort. } \\
\text { Kovariat: jenis kelamin, umur, riwayat } \\
\text { konsumsi alkohol, konsumsi kopi per } \\
\text { minggu, konsumsi ikan mentah, } \\
\text { konsumsi tomat, konsumsi retinol. }\end{array}$ & $\begin{array}{l}\text { Sampel berasal dari The Seoul } \\
\text { Male Cancer Cohort (SMCC) } \\
\text { yang merupakan database } \\
\text { untuk investigasi hubungan } \\
\text { berbagai faktor risiko dengan } \\
\text { kejadian kanker di Korea. } \\
\text { Dipilih } 7.009 \text { perokok sebagai } \\
\text { study partisipan dalam } \\
\text { penelitian ini, dimana sebanyak } \\
\text { 658 subjek dengan riwayat TB } \\
\text { paru. Follow up dilakukan } \\
\text { selama } 16 \text { tahun dari } 1 \text { Januari } \\
\text { 1993, sampai } \\
\text { 31 Desember } 2008 .\end{array}$ & $\begin{array}{l}\text { Crude RR dari riwayat TB terhadap } \\
\text { kejadian kanker paru } 2.01 \text { ( } 5 \% \text { CI: } 1.09- \\
\text { 3.47). Data yang sudah disesuaikan (usia, } \\
\text { asupan tomat dan kopi) RR dari riwayat } \\
\text { TB dalam terjadinya kanker paru pada } \\
\text { perokok 1,85 (95\% CI: } 1,08-3,19) \text {. } \\
\text { IR }=162,73 \text { per } 100.000 \text { orang tahun }\end{array}$ \\
\hline 8. & $\begin{array}{l}\text { Seri Hong'12 (Korea } \\
\text { Selatan) } \\
\text { International Journal } \\
\text { of Cancer: 139, 2447- } \\
2455 \text { (2016) }\end{array}$ & $\begin{array}{l}\text { Mengevaluasi asosiasi TB paru yang } \\
\text { sudah ada sebelumnya dengan } \\
\text { kejadian dan kematian akibat kanker } \\
\text { paru. } \\
\text { Kohort prospektif. } \\
\text { Kovariat: jenis kelamin, umur, status } \\
\text { merokok, jumlah rokok per hari, } \\
\text { lamanya merokok, konsumsi alkohol, } \\
\text { status ekonomi, status komorbiditas: } \\
\text { diabetes melitus, penyakit pada sistem } \\
\text { pernapasan. }\end{array}$ & $\begin{array}{l}\text { Sumber data The Korean Cancer } \\
\text { Prevention Study (KCPS) dan } \\
\text { The National Health Insurance } \\
\text { Service (NHIS). } \\
\text { Sebanyak } 60.081 \text { laki-laki dan } \\
\text { 19.217 perempuan memiliki } \\
\text { TB. } \\
\text { Rata-rata follow-up } 14,5 \text { tahun. }\end{array}$ & $\begin{array}{l}\text { Kejadian kanker paru (HR 1,37 pada laki- } \\
\text { laki, 95\% CI 1,29-1,45; HR 1,49 pada } \\
\text { perempuan, 95\% CI 1,28-1,74) } \\
\text { Kematian kanker paru (HR 1,43 pada laki- } \\
\text { laki, 95\% CI 1,34-1,52; HR 1,53 pada } \\
\text { perempuan, 95\% CI 1,28-1,83). } \\
\text { IR = 54,82 per } 100.000 \text { orang tahun. }\end{array}$ \\
\hline 9. & $\begin{array}{l}\text { Sue K. Park }{ }^{13} \text { (Korea } \\
\text { Selatan) } \\
\text { Lung Cancer Journal } \\
200905017\end{array}$ & $\begin{array}{l}\text { Menguji apakah kekuatan asosiasi } \\
\text { merokok berbeda menurut histologis } \\
\text { dan jenis kelamin, dan menilai faktor } \\
\text { risiko lain, khususnya TB, yang } \\
\text { berhubungan dengan risiko kanker } \\
\text { paru. } \\
\text { Kasus kontrol. } \\
\text { Kovariat: jenis kelamin, umur, riwayat } \\
\text { TB sebelumnya, riwayat kanker paru } \\
\text { pada keluarga, riwayat pekerjaan yang } \\
\text { berisiko, status merokok, jumlah rokok } \\
\text { per tahun, lamanya berhenti merokok. }\end{array}$ & $\begin{array}{l}\text { Kasus berasal dari The Korean } \\
\text { Academy of Tuberculosis and } \\
\text { Respiratory Diseases (KATRD), a } \\
\text { nationwide hospital-based lung } \\
\text { cancer study. Kontrol berasal } \\
\text { dari The Korean Multi Center } \\
\text { Cancer Cohort (KMCC). } \\
\text { Jumlah kasus sebanyak } 3.794 \\
\text { subjek. Kontrol sebanyak } 1.135 \\
\text { subjek. } \\
\text { Perbandingan kasus dan } \\
\text { kontrol 2:1 untuk laki-laki dan } \\
\text { 1:1 untuk perempuan. }\end{array}$ & $\begin{array}{l}\text { Di antara laki-laki, riwayat TB paru } \\
\text { memiliki OR 3,21 (95\% CI: 2,12-4,90) } \\
\text { untuk jenis karsinoma sel skuamosa, OR } \\
2,69 \text { ( } 95 \% \text { CI: 1,63-4,45) untuk jenis } \\
\text { adenokarsinoma, dan OR 1,52 ( } 95 \% \text { CI: } \\
\text { 0,83-2,78) untuk jenis karsinoma sel kecil. } \\
\text { Untuk wanita adalah OR 2,40 (95\% CI: } \\
\text { 1,30-4,42) untuk jenis karsinoma sel } \\
\text { skuamosa, OR 4,20 ( } 95 \% \text { CI: } 2,75-6,39) \\
\text { untuk jenis adenokarsinoma, dan OR 1,37 } \\
\text { (95\% CI: 0,61-3,06) untuk jenis karsinoma } \\
\text { sel kecil. }\end{array}$ \\
\hline 10. & $\begin{array}{l}\begin{array}{l}\text { Rachel Denholm } \\
\text { (Eropa dan Kanada) }\end{array} \\
\text { American Journal of } \\
\text { Respiratory and } \\
\text { Critical Care Medicine } \\
\text { Vol 190, Iss 5, pp } \\
\text { 549-559, Sep 1, 2014 }\end{array}$ & $\begin{array}{l}\text { Menginvestigasi risiko kanker paru } \\
\text { yang terkait dengan kronis bronkitis, } \\
\text { emfisema, TBC, pneumonia, dan asma. } \\
\text { Kasus kontrol. } \\
\text { Kovariat: jenis kelamin, umur, tingkat } \\
\text { pendidikan, pekerjaan, status } \\
\text { merokok, jumlah rokok per tahun, } \\
\text { lama dalam tahun berhenti merokok. }\end{array}$ & $\begin{array}{l}\text { Penelitian ini merupakan } \\
\text { Proyek SYNERGY yang } \\
\text { mengumpulkan informasi } \\
\text { riwayat penyakit pernapasan } \\
\text { dari } 7 \text { studi kasus kontrol yang } \\
\text { dilakukan di Eropa danKanada. } \\
\\
\text { Sebanyak } 12.739 \text { subyek kasus } \\
\text { dan } 14.945 \text { kontrol. }\end{array}$ & $\begin{array}{l}\text { Tidak ada hubungan antara TBC dan } \\
\text { kanker paru terhadap data yang diamati; } \\
\text { OR 1,00 ( } 95 \% \text { CI, 0,83 - 1,20). } \\
\text { Hubungan antara latensi penyakit paru } \\
\text { sebelumnya dan kanker paru; TBC yang } \\
\text { didiagnosis 2-4 tahun sebelumnya } \\
\text { memiliki OR 3,76 ( } 95 \% \text { CI, 1,05-13,56) } \\
\text { untuk laki-laki. }\end{array}$ \\
\hline
\end{tabular}

*IRR: Insidens rate ratio, IR: Incidence Rates, SIR: standardized, incidence ratio, RR: relative risk, HR: hazard ratios, CI: confidence interval 
konsisten menunjukkan hubungan secara statitstik bermakna dengan kisaran nilai RR 1,37-6,1. Insidens rate kejadian kanker paru pada penderita tuberkulosis paru dari hasil studi tinjauan pustaka ini berkisar antara 0,2 per 1000 orang-tahun sampai dengan $11.628,06$ per 100.000 orang-tahun.

Dari dua penelitian kasus kontrol ${ }^{13-14}$ dengan tujuan penelitian yang sama, menunjukkan terdapat hubungan infeksi TB paru dengan kanker paru secara statitstik bermakna hanya pada satu penelitian ${ }^{13}$ dengan kisaran nilai OR 1,52 - 3,21 spesifik pada jenis sel kanker paru tertentu. Namun pada penelitian dengan desain yang sama, ${ }^{14}$ risiko terhadap terjadinya kanker paru secara positif dibuktikan dari subjek dengan riwayat penyakit paru lainnya yaitu bronkhitis kronik dan emfisema.

Beberapa studi $\mathrm{i}^{4,7,8}$ menampilkan prediksi interval waktu sejak terdiagnosanya TB paru hingga berkembang menjadi kanker paru. Dalam 33 tahun pengamatan, risiko terjadinya kanker paru pada pasien TB dibandingkan populasi umum adalah 3,40 lebih tinggi (SIR [standardized incidence ratio] 3,40; 95\%CI 3,09-3,74). Tiga bulan setelah TB paru risiko absolut terjadinya semua jenis kanker adalah 1,83\%, dan bila dibandingkan dengan populasi umum, pasien dengan TB paru aktif berisiko 11,09 kali lebih tinggi untuk mendapatkan semua jenis kanker (SIR 11,09; 95\%CI 9,82-12,48) dimana peningkatan nilai SIR khusus untuk mesothelioma dan kanker paru berturut-turut adalah 368,4 dan kanker paru 40,9; dalam periode waktu tiga bulan sampai dengan lima tahun risiko untuk semua kanker adalah 1,59 (SIR 1,59; 95\% CI 1,46-1,72) dimana nilai SIR khusus untuk mesothelioma dan kanker paru berturut-turut adalah 19 dan 3. Untuk periode lebih dari 5 tahun, risikonya terjadinya semua kanker adalah 1,17 lebih tinggi (SIR 1,17; 95\% CI 1,101,25). ${ }^{4}$ Risiko kematian karena kanker paru dalam lima tahun pertama setelah terdiagnosis TB paru adalah 3,4 kali lebih tinggi dibanding pasien yang tanpa TB paru, (nilai HR berkisar dari 6,7-13), dan risiko tersebut tetap tinggi pada pada 5-9,9 tahun setelah terdiagnosis TB (HR 3,4; 95\% CI 1,3-9,1) dan yang terdiagnosa pada lebih dari 10 tahun risikonya 3,0 kali (HR 3,0; 95\% CI 1,3-7,3). ${ }^{7}$ Dibandingkan populasi umum, pada 2-4 tahun setelah terdiagnosa TB berisiko 1,98 kali untuk mejadi kanker paru; 1,42 kali pada 5-7 tahun; dan 1,59 pada 8-12 tahun setelah infeksi TB. ${ }^{8}$

Salah satu penelitian juga memberikan prediksi bahwa TB adalah faktor risiko potensial untuk tipe histologis dari kanker paru tertentu, dimana riwayat TB paru dikaitkan dengan peningkatan risiko untuk karsinoma sel skuamosa dan adenokarsinoma, tetapi tidak untuk karsinoma sel kecil pada laki-laki. ${ }^{13}$ dan beberapa penelitian mengungkapkan bahwa TB paru menjadi prediktor terhadap beberapa kanker yang spesifik selain kanker paru, ${ }^{4,10}$ nilai SIR pada keganasan bukan paru meningkat pada kelompok dengan TB $(1,71$, 95\% CI, 1,54-1,90). Untuk laki-laki, SIR meningkat dalam waktu 1 tahun setelah diagnosis TB untuk kanker: kepala dan penyakit leher, kerongkongan, kolorektal, hati, paru, melanoma, dan Hodgkin. Untuk perempuan, SIR meningkat untuk leukemia, esofagus, dan kanker paru dalam tahun pertama. ${ }^{10}$

\section{Pembahasan}

Dalam studi ini penulis memberikan gambaran mengenai risiko kejadian kanker paru diantara penderita TB paru. Populasi studi dalam tinjauan pustaka ini sebagian besar adalah negara dengan jumlah kasus TB paru yang tinggi yaitu Taiwan, ${ }^{3,8-10} \mathrm{Cina},{ }^{7}$ dan Korea Selatan. ${ }^{11-13}$ Terkecuali pada artikel, ${ }^{14}$ dimana jumlah subyek dengan TB dalam konsorsium ini sedikit, dan berasal dari beberapa negara di Eropa dan Kanada.

Tuberkulosis adalah penyebab utama morbiditas, terutama di negara berkembang. China memiliki beban penyakit sangat tinggi akibat TB diperkirakan 1,3 juta kasus TB. ${ }^{15}$ Korea memiliki substansial beban TB. Estimasi prevalensi rate TB paru aktif (konfirmasi bakteriologis) adalah 146 per 100.000 tahun 2012 dan 143 per 100.000 tahun 2013, sebanding dengan rate pada "high-TB burden countries". ${ }^{16} \mathrm{Di}$ antara penyakit menular di Taiwan, TB memiliki tingkat kejadian tertinggi untuk sepuluh tahun terakhir. Pada 2012, ada 53 kasus baru per 100.000 populasi di Taiwan. ${ }^{17}$

Kanker paru merupakan beban penyakit keganasan utama di dunia, merupakan kanker yang paling umum terjadi. Kanker paru menyumbang $17 \%$ dan 9\% dari semua kanker pada laki-laki dan perempuan. ${ }^{18}$ Di Korea dan Cina, kanker paru merupakan kanker yang menempati urutan teratas dari seluruh kanker baik pada laki-laki dan perempuan yaitu sebesar 12.778 kasus atau 23\% untuk Korea, sementara $774.323(18,1 \%)$ di Cina. ${ }^{5}$ Sementara Indonesia, kanker paru menempati urutan ketiga dari keseluruhan kanker pada laki-laki dan perempuan yaitu sebesar $30.023(8,6 \%)^{2}$

Hubungan yang jelas antara risiko kejadian kanker paru pada penderita tuberkulosis paru terus mengalami perkembangan, dalam tulisan ini secara ringkas diuraikan hubungan biological plausibility. Ada beberapa mekanisme potensial dimana TB dan riwayat penyakit paru kronis lainnya dapat meningkatkan risiko untuk kanker paru. Salah satu mekanismenya adalah adanya peradangan kronis lokal dan stres 
oksidatif. ${ }^{19}$ Mekanisme kekebalan tubuh juga relevan, infeksi tuberkulosis menyebabkan tubuh menghasilkan respon imun yang besar dan dalam waktu yang panjang, sel-sel inflamasi di paru menghasilkan pensinyalan sitokin yang luas dapat merangsang pertumbuhan dan perkembangan tumor, nitrogen dan oksigen reaktif yang dihasilkan oleh neutrofil teraktivasi dapat berikatan dengan DNA, memicu kerusakan genetik dan transformasi proses neoplastik, prostaglandin dan protease dapat merusak jaringan. ${ }^{20}$

Gejala TB terjadi beberapa bulan sebelum diagnosis, dan pengobatan untuk TB diberikan selama periode waktu yang lama, sehingga pada pasien TB yang menerima pengobatan mungkin memiliki peradangan paru yang berkepanjangan sehingga menginduksi peradangan paru yang substansial selama periode ini. ${ }^{7}$ Pada gilirannya, peradangan paru yang berkepanjangan dapat menyebabkan kerusakan jaringan dan perubahan genom. Selanjutnya, perbaikan kerusakan jaringan yang disebabkan oleh TB dapat menyebabkan fibrosis paru dan jaringan parut ${ }^{20}$ Dalam suatu studi menemukan bahwa laki-laki yang didiagnosis dengan gejala sisa TB memiliki peningkatan risiko kanker paru. Diagnosis ini dimungkinkan sebagai akibat dari kerusakan paru yang berat karena infeksi TB, pengamatan ini mendukung pentingnya fibrosis dalam mempromosikan proses karsinogenesis. ${ }^{21}$

Pada studi tinjauan pustaka ini terdapat delapan penelitian dengan desain kohor. ${ }^{3-4,7-12}$ Kekuatan pada desain studi ini adalah pembuktian terhadap temporality, sehingga dapat dipastikan pajanan terjadi lebih dahulu daripada penyakit dan dapat dilihat bagaimana kecepatan terjadinya penyakit atau periode sejak terinfeksi TB paru hingga menjadi kanker paru. Jurnal dalam studi tinjauan pustaka secara konsisten menggambarkan risiko kejadian kanker paru pada penderita tuberkulosis paru setelah dikontrol beberapa variabel perancu.

Pada salah satu jurnal dengan desain kohort prospektif mengeksplorasi hubungan secara longitudinal antara TB dan risiko kanker paru, dengan sumber data yang berasal dari populasi, serta penetapan secara ketat verifikasi data untuk memastikan diagnosis. Studi ini secara signifikan membuktikan kejadian kanker paru lebih besar terjadi pada pasien dengan TB daripada populasi umum. ${ }^{3}$ Pada studi ${ }^{4,7,8}$ dengan desain kohort retrospektif, didapatkan prediksi interval waktu sejak terdiagnosanya TB paru berkembang menjadi kanker paru.

Kekuatan dalam studi tinjauan pustaka ini adalah jurnal rujukan menggunakan data berbasis populasi yang bersumber dari asuransi kesehatan nasional, ${ }^{3,8-10,12}$ registrasi penyakit nasional, ${ }^{4,13}$ data kohort populasi untuk faktor risiko, ${ }^{11-13}$ konsorsium dari beberapa negara, ${ }^{14}$ sehingga melibatkan sampel yang besar dengan menggunakan catatan medik yang terdokumentasi dengan baik.

Adapun kekurangan dalam beberapa jurnal dalam studi tinjauan pustaka ini yaitu penelitian yang dilakukan dengan desain kasus kontrol ${ }^{13-14}$ sangat rawan dengan recall bias, terutama jika riwayat diagnosis ataupun variabel faktor risiko didapatkan berdasarkan pelaporan sendiri, kurang lengkapnya catatan medis, dan perbedaan populasi antara kasus dan kontrol yang dapat menyebabkan perbedaan karakteristik walaupun matching dilakukan untuk mengurangi bias akibat perbedaan ini. Sementara kekurangan dalam kohort restrospektif dalam studi tinjauan pustaka ini adalah kesalahan dalam pengelompokkan data dasar yang diambil berdasarkan kode penyakit dan riwayat pengobatan, riwayat faktor risiko lainnya yang juga merupakan perancu terhadap terjadinya kanker paru tidak tersedia dalam dokumentasi yang ada. Sehingga beberapa artikel tidak dapat menyajikan risiko yang lebih valid karena ketidaklengkapan sumber informasi yang tersedia.

Namun, dari hasil yang telah dijabarkan dapat memberikan bukti secara epidemiologi yang solid bahwa TB paru merupakan faktor risiko terhadap terjadinya kanker paru ${ }^{8}$ juga pada TB paru dengan status perokok aktif ${ }^{13}$ bahkan pada bukan perokok, ${ }^{12}$ sebagai tambahan bahwa penyakit paru obstruktif kronik (PPOK) dan rokok memberikan dukungan terhadap peningkatan risiko ini. ${ }^{14}$

TB secara substansial meningkatkan risiko kanker selain kanker paru seperti keganasan pada pleura mesothelioma dan lymphoma. ${ }^{4}$ Pada populasi pedesaan, didapatkan bahwa risiko TB meningkat secara signifikan di antara penduduk dengan status sosial ekonomi dan tingkat pendidikan yang rendah dan tempat tinggal yang hanya memiliki satu ruangan, hubungan yang substansial juga terlihat dengan meningkatnya risiko TB di antara individu dengan asma, bronkitis kronis, dan emfisema ${ }^{7}$ serta penyakit paru lainnya tersebut sebagai faktor risiko terhadap terjadinya kanker paru.,14

Artikel lainnya mengungkapkan bahwa adanya peningkatan risiko untuk kanker spesifik selain kanker paru setelah infeksi TB dan berbeda antara jenis kelamin dan interval waktu setelah diagnosa TB. ${ }^{9}$ Selain itu terdapat bukti tambahan bahwa TB adalah faktor risiko potensial untuk tipe histologis tertentu dari kanker paru. ${ }^{13}$ Kejadian beberapa kanker selain kanker paru juga meningkat pada subjek dengan infeksi TB 
Secara garis besar artikel di dalam studi ini konsisten dan sejalan dengan tinjauan pustaka sistematis yang pernah dilakukan terhadap 41 studi, menyimpulkan bahwa hubungan antara TB dan risiko kanker paru secara signifikan meningkat, terlepas status merokok atau interval waktu dari diagnosis TB, hubungan TB dengan jenis histologi adenokarsinoma paru tercatat terutama terjadi di negara bukan barat. Dampak TB pada kanker paru bervariasi di antara berbagai kelompok etnis dan di daerah yang berbeda. ${ }^{22}$

Dalam tinjauan pustaka sistematis dan meta analisis yang diterbitkan pada tahun 2011, diagnosis TB sebelumnya dikaitkan dengan peningkatan risiko kanker paru (risiko relative 1,76 [95\% CI 1.49-2.08] dengan sedikit variasi berdasarkan status merokok. ${ }^{23}$ Serupa dengan hasil dari International Lung Cancer Consortium, menemukan RR kanker paru sebesar 1,48 [95\% CI 1.17-1.87] terkait dengan riwayat TB, setelah mengendalikan status merokok. ${ }^{24}$

Peningkatan insiden kanker paru menunjukkan kecenderungan pergeseran dari negara maju ke negara kurang berkembang, ${ }^{25}$ dimana TB masih merupakan masalah kesehatan yang utama karena kemiskinan, kepadatan penduduk tinggi, lingkungan yang tidak memadai, dan kurang aksesibilitas ke perawatan kesehatan. Prevalensi merokok yang tinggi dan ventilasi rumah yang tidak memadai menunjukkan adanya potensi beban kesehatan risiko kanker paru terkait dengan TB, menegaskan perlunya pengendalian TB dan rokok di negara berkembang. ${ }^{3}$

\section{Kesimpulan}

Studi tinjauan pustaka ini memberikan gambaran mengenai risiko kejadian kanker paru diantara penderita TB paru, membuktikan secara epidemiologi bahwa TB paru merupakan salah satu faktor risiko terhadap terjadinya kanker paru. Penulisan ini menjadi masukan bagi klinisi agar melakukan pemantauan yang lebih hati-hati pada pasien TB paru sebagai upaya preventif terhadap terjadinya kanker paru. Bagi pembuat kebijakan kesehatan, bermanfaat dalam memprediksi peningkatan risiko jangka panjang terhadap terjadinya kanker paru, terlebih pada populasi dengan prevalensi TB yang tinggi, seperti Indonesia.

Penulisan lebih lanjut tinjauan kepustakaan sistematis dan meta-analisis perlu dilakukan dan penelitian perlu dilaksanakan dalam ruang lingkup yang berbeda di Indonesia, baik tingkat rumah sakit ataupun populasi agar mendapat gambaran awal terhadap situasi yang terjadi. Hasil dari studi ini dapat menjadi inisiator gambaran TB paru sebagai faktor risiko terhadap kejadian kanker paru di Indonesia.

\section{Ucapan Terima Kasih}

Penulis mengucapkan terima kasih kepada Lembaga Pengelola Dana Pendidikan(LPDP) Kementerian Keuangan yang telah memberikan dukungan finansial melalui Beasiswa Pendidikan Indonesia tahun 2018.

\section{Daftar Pustaka}

1.Kementerian Kesehatan. Infodatin TB 2018. https:// pusdatin.kemkes.go.id/article/view/18101500001/ infodatin-tuberkulosis-2018.html

2.World Health Organization. Indonesia Source GLOBOCAN 2018. Int Agency Res Cancer [Internet]. 2019;256:1-2. Available from: http://gco.iarc.fr/.

3.Yu YH, Liao CC, Hsu WH, Chen HJ, Liao WC, Muo CH, et al. Increased lung cancer risk among patients with pulmonary tuberculosis: A population cohort study. J Thorac Oncol [Internet]. Elsevier; 2011;6(1):32-7.

4.Simonsen DF, Farkas DK, Søgaard M, Horsburgh CR, Sørensen HT, Thomsen RW. Tuberculosis and risk of cancer: A Danish nationwide cohort study. Int J Tuberc Lung Dis. 2014;18(10):1211-9.

5.Ferlay, Jacques, et al. Estimating the global cancer incidence and mortality in 2018: GLOBOCAN sources and methods. International journal of cancer 144.8 (2019): 1941-1953.

6.Cicenas S, Vencevièius V. Lung cancer in patients with tuberculosis. World J Surg Oncol. 2007;5(1991):1-5.

7.Engels EA, Shen M, Chapman RS, et al. Tuberculosis and subsequent risk of lung cancer in Xuanwei, China. Int J Cancer. 2009;124(5):1183-1187.

8.Wu CY, Hu HY, Pu CY, Huang N, Shen HC, Li CP, et al. Pulmonary tuberculosis increases the risk of lung cancer. Cancer. 2011;117(3):618-24.

9.Kuo SC, Hu YW, Liu CJ, Lee YT, Chen YT, Chen TL, et al. Association between tuberculosis infections and nonpulmonary malignancies: A nationwide population-based study. Br J Cancer. 2013;109(1):229-34.

10.Su VYF, Yen YF, Pan SW, Chuang PH, Feng JY, Chou KT, et al. Latent tuberculosis infection and the risk of subsequent cancer. Med (United States). 2016;95(4):1-6.

11.Bae JM, Li ZM, Shin MH, Kim DH, Lee MS, Ahn YO. Pulmonary tuberculosis and lung cancer risk in current smokers: The Seoul male cancer cohort study. J Korean Med Sci. 2013;28(6):896-900.

12.Hong S, Mok Y, Jeon C, Jee SH, Samet JM. Tuberculosis, smoking and risk for lung cancer incidence and mortality. Int J Cancer. 2016;139(11):2447-55. 
13.Park SK, Cho LY, Yang JJ, Park B, Chang SH, Lee KS, et al. Lung cancer risk and cigarette smoking, lung tuberculosis according to histologic type and gender in a population based case-control study. Lung Cancer.

14.Denholm R, Schüz J, Straif K, Stücker I, Jöckel KH, Brenner $\mathrm{DR}$, et al. Is previous respiratory disease a risk factor for lung cancer? Am J Respir Crit Care Med. 2014;190(5):54959.

15.Organization WH, Organization WH. Global tuberculosis control/ : surveillance, planning, financing/ : WHO report 2007 [Internet]. Geneva PP - Geneva: World Health Organization; Available from: https://apps.who.int/iris/ handle/10665/43629

16.Organization WH. Global tuberculosis report 2014 [Internet]. Geneva PP - Geneva: World Health Organization; Available from: https://apps.who.int/iris/handle/10665/ 137094.

17.Dirlikov E, Raviglione M, Scano F. Global Tuberculosis Control: Toward the 2015 Targets and Beyond. Ann Intern Med. United States; 2015 Jul;163(1):52-8.

18.Torre LA, Bray F, Siegel RL, Ferlay J, Lortet-Tieulent J, Jemal A. Global cancer statistics, 2012. CA Cancer J Clin. 2015;65:87-108.

19.Alberg AJ, Brock M V, Ford JG, Samet JM, Spivack SD. Epidemiology of lung cancer: Diagnosis and management of lung cancer, 3rd ed: American College of Chest Physicians evidence-based clinical practice guidelines. Chest. United States; 2013 May;143(5 Suppl):e1S-e29S.
20.Nalbandian A, Yan BS, Pichugin A, Bronson RT, Kramnik I. Lung carcinogenesis induced by chronic tuberculosis infection: the experimental model and genetic control. Oncogene. 2009;28(17):1928-1938.

21.Shiels MS, Albanes D, Virtamo J, Engels EA. Increased risk of lung cancer in men with tuberculosis in the alphatocopherol, beta-carotene cancer prevention study. Cancer Epidemiol Biomarkers Prev. 2011;20(4):672-678.

22.Liang H-Y, Li X-L, Yu X-S, Guan P, Yin Z-H, He Q-C, et al. Facts and fiction of the relationship between preexisting tuberculosis and lung cancer risk: a systematic review. Int J cancer. United States; 2009 Dec;125(12):2936-44.

23.Brenner DR, McLaughlin JR, Hung RJ. Previous lung diseases and lung cancer risk: a systematic review and metaanalysis. PLoS One. United States; 2011 Mar;6(3):e17479.

24.Brenner DR, Boffetta P, Duell EJ, Bickeboller H, Rosenberger A, McCormack V, et al. Previous lung diseases and lung cancer risk: a pooled analysis from the International Lung Cancer Consortium. Am J Epidemiol United States; 2012 Oct,176(7):573-85.

25.Youlden DR, Cramb SM, Baade PD. The International Epidemiology of lung cancer: geographical distribution and secular trends. J Thorac Oncol 2008;3:819 - 831. 